\title{
Incidence of Cervical Cerclage and Preterm Birth Rates: A Retrospective Analysis of Data from Two Centers in Croatia
}

\author{
Gordana Planinić-Radoš ${ }^{1 *}$, Herman Haller ${ }^{2,4}$, Žana Žegarac ${ }^{1}$, Sandra Stasenko ${ }^{1,3}$ and Željko Duić ${ }^{1,3}$ \\ ${ }^{1}$ Department of Obstetrics and Gynecology, University Hospital Merkur, Croatia \\ ${ }^{2}$ Department of Obstetrics and Gynecology, University Hospital Rijeka, Croatia \\ ${ }^{3}$ School of Medicine, University of Zagreb, Croatia \\ ${ }^{4}$ School of Medicine, University of Rijeka, Croatia
}

Submission: June 25, 2020; Published: July 02, 2020

*Corresponding author: Gordana Planinić-Radoš, Department of Obstetrics and Gynecology, University Hospital Merkur, Croatia

\section{Abstarct}

Aim of the study: In recent period significant changes in the indications for cerclage procedure have emerged. Published trials caused shift in clinical practice with the reduction in the number of procedures worldwide. Analysis was undertaken to evaluate how did the more selective approach to patients who were candidates for cervical cerclage affect the preterm birth rates.

Methods: We conducted a retrospective analysis of women who underwent cerclage for prevention of preterm birth in two Croatia's hospitals, University hospital Merkur (Zagreb) and University hospital Rijeka (Rijeka) over a 16-year period, from 1994 to 2009. Data from medical records were used to determine the total number of cervical cerclage procedures performed on singleton pregnancies and to calculate incidence rates. Annual hospital reports were used to calculate preterm birth rates in the same period.

Results: From 1994 to 2009 in both centers there were 81800 singleton deliveries including 3847 preterm births (4.7\%). Of all deliveries 977 women $(1.19 \%)$ received cerclage and were included in the analysis. A significant linear decrease of cervical cerclage rate across the whole time from 1994 to 2009 was observed. Over the 16 year period there was no statistically significant change in the percentage of preterm births.

Conclusion: More appropriate selection of patients who are candidates for cervical cerclage reduced the number of unnecessary procedures from $2.71 \%$ in 1994 to $0.69 \%$ in 2009 without significant increase in preterm birth rates.

Keywords: Cerclage; Preterm birth; Incidence; Hight risk pregnancy; Pregnancy

\section{Introduction}

Preterm birth and subsequently prematurity are a major cause of neonatal morbidity and mortality. Although preterm birth is defined as delivery before $37+0$ weeks of gestation, most of the adverse outcomes are related to birth before $33+0$ weeks of gestation. Rates of infant mortality in this gestational age group range from 10 to $15 \%$ [1]. Global estimates of the incidence of preterm birth are difficult to make due to lack of quality data especially in underdeveloped countries. However in 2010. in systematic analysis published by World Health Organisation (WHO) worldwide incidence was estimated at 11.1 per 100 live births [2]. Despite of advances in diagnosis and treatment, time trends suggest that incidence is increasing in most countries. Several risk factors for preterm birth have been identified. Women with history of spontaneous second trimester miscarriage and preterm delivery are at increased risk for preterm birth in a subsequent pregnancy. Another important risk factor and a powerful predictor of spontaneous preterm birth is cervical length shortening $(<25 \mathrm{~mm})$ before 24 week of gestation. Cervical cerclage is surgical treatment initially used in singleton pregnant women with cervical incompetence for preventing recurrent loss. Method was first introduced by Shirodkar in 1955 as a transvaginal circular suture inserted above the level of the cardinal ligaments after bladder mobilisation [3]. Shortly after simplification of the method was made by McDonald by inserting suture at the cervico-vaginal junction without bladder mobilisation [4]. Although cerclage presents a structural support to a incompetent cervix, it seems that more important mechanism of action lies in supporting endocervical mucus plug as a barrier to ascending infections. The efficacy of cerclage is uncertain and it primarily depends on indication for procedure. Since the 
indications of placement of cerclage have changed in recent years, with significant reduction in the overall number of procedures, it is important to evaluate how it affected the number of premature births. The objective of this study was to investigate the impact of reduction in the number of cervical cerclage procedures on the overall rate of preterm births in women with singleton gestations in two centers in Croatia. Analysis is based on traceable patient records undertaken at the University hospital Merkur (Zagreb) and University hospital Rijeka (Rijeka), two Croatia's referral and teaching hospitals.

\section{Material and Methods}

We conducted a retrospective analysis of all patients with singleton pregnancies who underwent cerclage for prevention of PTB in the Division of Maternal and Fetal Medicine, Department of Obstetrics and Gynecology of University hospital Rijeka (Rijeka, Croatia) and University hospital Merkur (Zagreb, Croatia) in a period from 1994 to 2009. Patients were identified through surgical protocols of cerclage procedures and medical records. All singleton pregnancies with cerclage procedure performed because of poor obstetric history (two or more spontaneous second trimester pregnancy loss or preterm birth) or short cervical length findings $(<25 \mathrm{~mm})$ on ultrasound examination before 24 weeks of gestation met the inclusion criteria. Patients with cerclage being performed after clinical examination because of painless, progressive dilatation $(>3 \mathrm{~cm})$ of the cervix and imminent preterm delivery before 23 weeks of gestation (rescue cerclage) were also included in the analysis. We excluded all multiple gestations since, at time, there was no evidence of benefit from cerclage in this population [5]. Total number of term and preterm births for each year of the study were obtained from annual hospital reports. Statistical analysis was performed using Statistical Package for Social Scientist (SPSS version 20). Cervical cerclage rates and its correlation to preterm birth rates were analysed in observed period. Linear regressions were performed to calculate $\mathrm{R}$ and adjusted R2 (aR2) values, and p-values. P values less than 0.05 were considered statistically significant. Chi-squared test was performed for time trends analysis.

\section{Result}

From 1994 to 2009 in both centers there were 81800 singleton deliveries including 3847 preterm births (4.7\%). Of all deliveries 977 women (1.19\%) received cerclage and were included in the analysis. Over the 16 year period there was no statistically significant change in the percentage of preterm births $(<36+6$ weeks $)(\mathrm{R}=0.487 ; \mathrm{aR} 2=0.183 ; \mathrm{p}=0.056)$ (Figure 1$)$. Statistical analysis for each center separately showed that there was no significant change in the percentage of preterm births in the University hospital Rijeka ( $=0.355$; $\mathrm{aR2}=0.063$; $\mathrm{p}=0.178$ ) (Figura 1a), as well as in University hospital Merkur ( $\mathrm{R}=0.340$; aR2 $=0.053 ; \mathrm{p}=0.197$ ) (Figure 1b). When aggregated data are analysed for both institutions the incidence rate of cerclage (procedures per 100 births) decreased significantly $(\mathrm{R}=0.860 ; \mathrm{aR} 2=0.721 ; \mathrm{p}<0.05)$ (Figure 2). The chi-squared test for trend suggested a significant linear decrease of cervical cerclage rate across the whole time from 1994 to 2009 ( $p<0.05)$. Separate analysis for each institution shows reduction in the number of procedures in University hospital Rijeka, however without statistical significance $(R=0.410$; $\mathrm{aR}=0.109 ; \mathrm{p}=0.115$ ) (Figure 2a). In University hospital Merkur statistically significant reduction in the incidence rate of cerclage procedures was noted $(\mathrm{R}=0.913$; $\mathrm{aR} 2=0.822 ; \mathrm{p}<0.005)$ (Figure $2 \mathrm{~b})$. When analyzed together, data for both institutions show that there was no correlation between the number of cervical cerclage procedures and preterm birth rates $(p=0.792)$ (Figure 3). Success rate of cervical cerclage (defined as term births in women with cerclage stitch) for both institutions in observed period was $81 \%$. The incidence of preterm birth in women with cervical cerclage decreased slightly but statistically significant during reported period $(\mathrm{R}=0.543 ; \mathrm{aR} 2=0.245 ; \mathrm{p}=0.03)$ (Figure 4). Out of all preterm births, $4.75 \%$ were preterm births in patients with cervical cerclage.

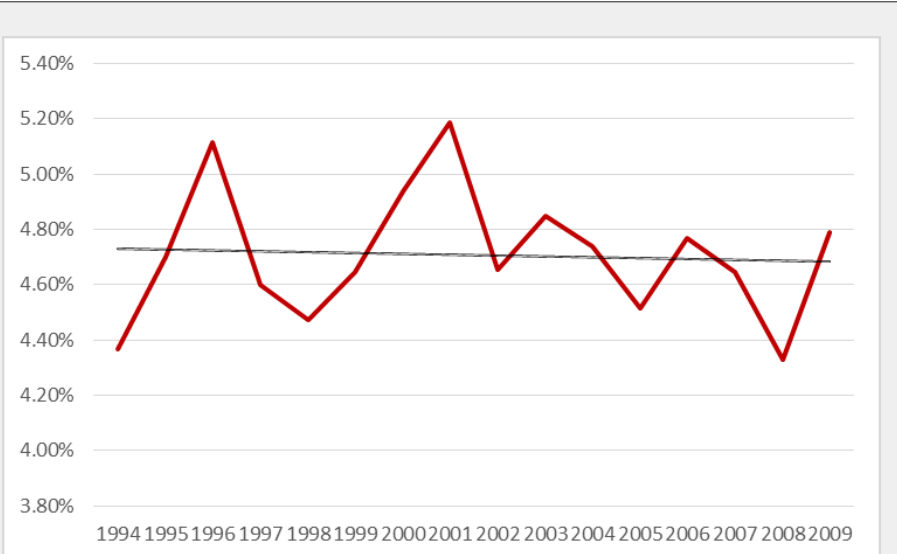

Figure 1: Preterm births as a percentage of all births in University hospital Rijeka and University hospital Merkur, Croatia from 1994 to 2009. 


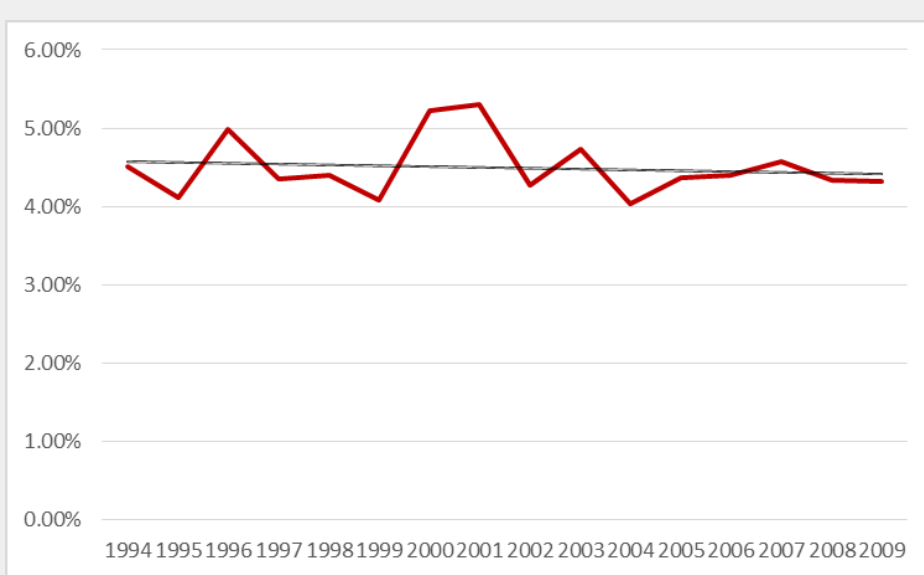

Figure 1a: Preterm birth rate in University hospital Rijeka.

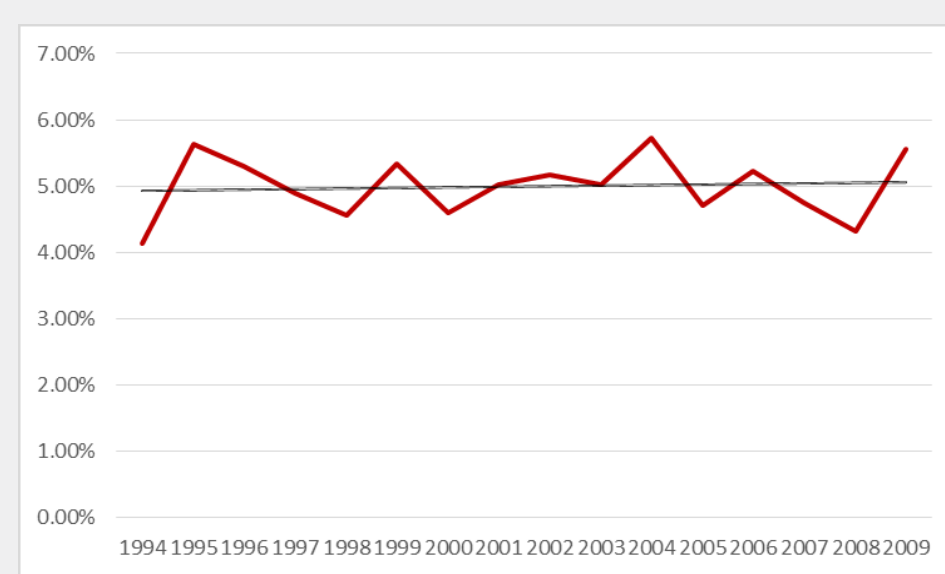

Figure 1b: Preterm birth rate in University hospital Merkur.

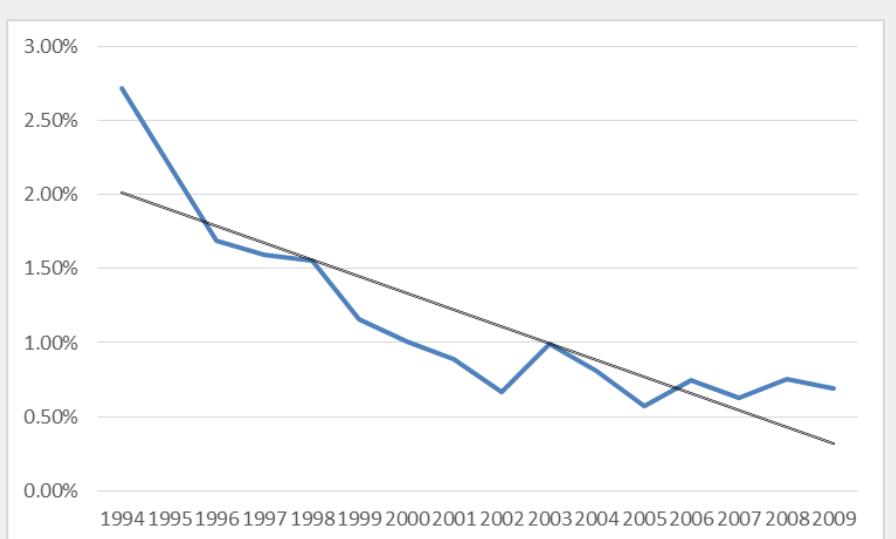

Figure 2: Overall incidence rate of cervical cerclage (procedures per 100 births) in University hospital Rijeka and University hospital Merkur for the period 1994 until 2009. 


\section{Journal of Gynecology and Women's Health}

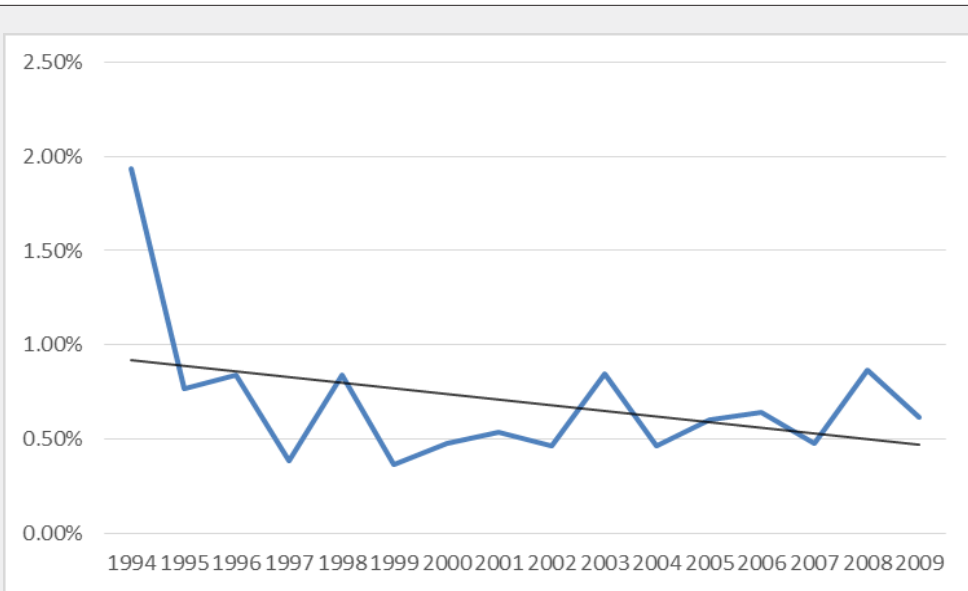

Figure 2a: Incidence rate of cervical cerclage in University hospital Rijeka.

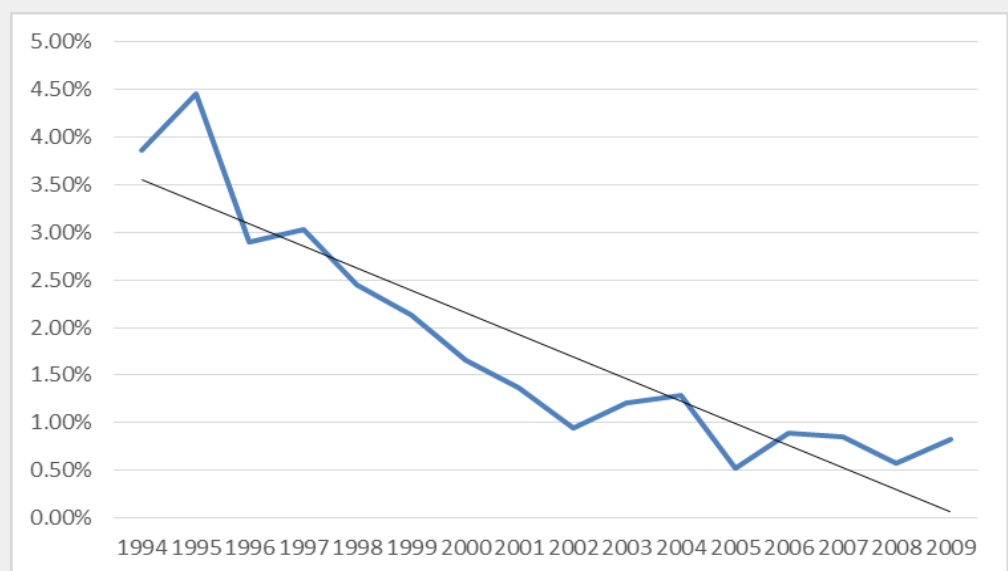

Figure $\mathbf{2 b}$ : Incidence rate of cervical cerclage in University hospital Merkur.

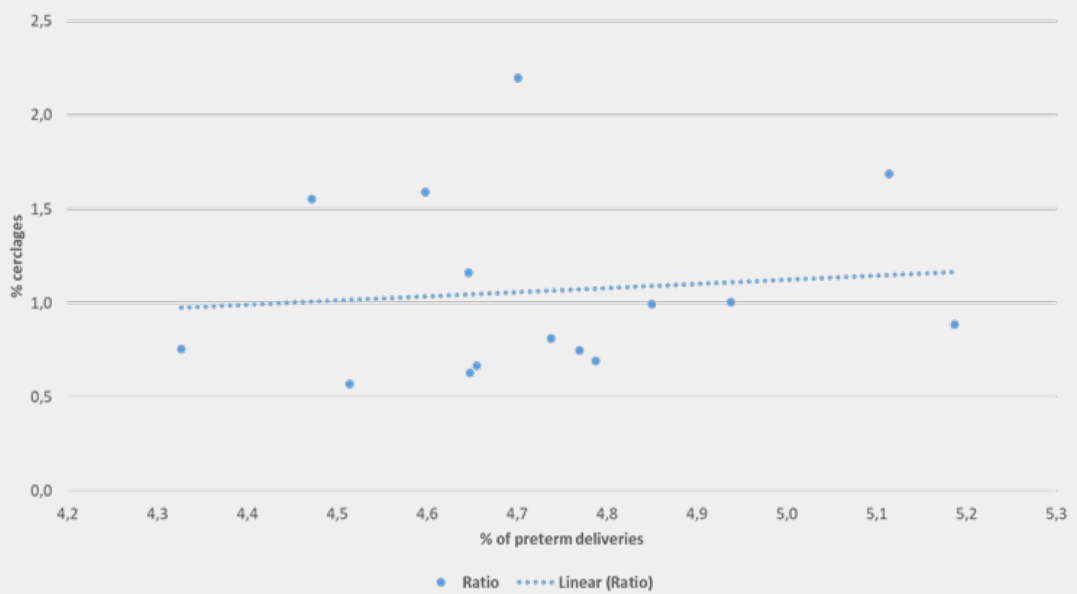

Figure 3: An impact of cervical cerclage rate on preterm deliveries. 


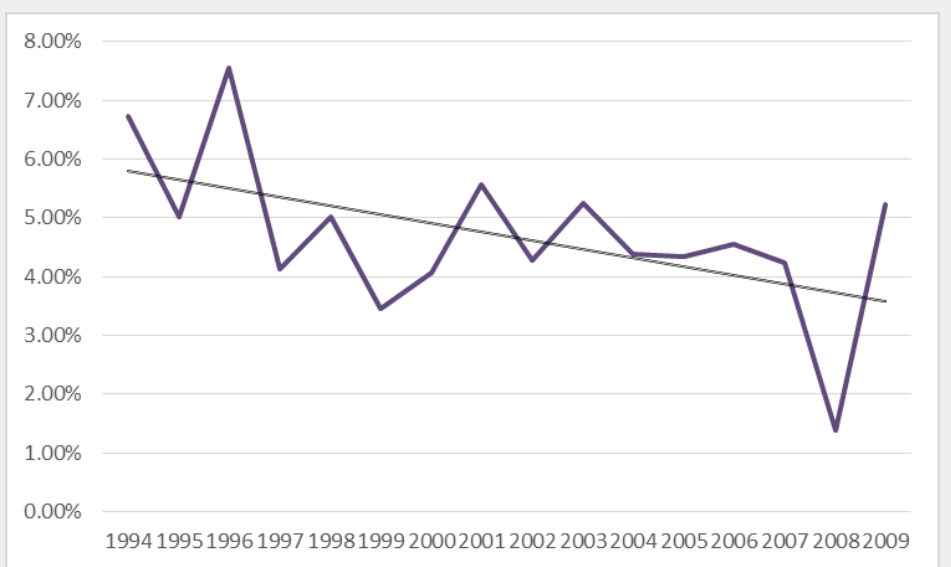

Figure 4: Preterm birth rate in women with cervical cerclage in University hospital Rijeka and University hospital Merkur for the period 1994 until 2009.

\section{Discussion}

During 16 years period, significant decline in overall rate of cerclage procedures was recorded in both of our institutions from $2.71 \%$ in 1994 to $0.69 \%$ in 2009. In University hospital Rijeka overall rate of cervical cerclage was $0.69 \%$. Significant reduction in number of procedures was noted in 1995 where cervical cerclage rate fell and remained under $1 \%$ in following years, ranging from $0.86 \%$ to $0.36 \%$. During reported period overall cervical cerclage rate in University hospital Merkur was 1.86\% with highest incidence during 1994-95 period, above 4\%. Reduction in number of cervical cerclage in singleton pregnancies was noted from year 2005 with annual incidence under 1\%. Explanation for the reduction in the number of cerclage procedures can be found in reduction of history indicated cerclage. In the mentioned period several randomized controlled trials and meta-analysis were published that changed clinical practice regarding the history indicated cerclage as a intervention for preventing of preterm birth [6,7]. Bulk of evidence was additionally supported by the largest randomised controlled trial comparing historyindicated cerclage with expectant management, published by the Medical Research Council and Royal College of Obstetricians and Gynaecologists [8]. Study showed that there were fewer deliveries before 33 weeks of gestation in the cerclage group compared with the controls. However subgroup analysis showed that reduction in preterm birth rates was only significant in a group of women with a history of three or more pregnancies ending before 37 weeks of gestation. In our centers certain groups of women who would traditionally be candidates for history indicated cerclage were observed with cervical stitch being placed only in cases where cervical length shortening or progressive dilatation is verified on clinical examination. In this way additional selection of patient who would benefit most from cerclage procedure was achieved and number of unnecessary cerclage procedure was reduced. Support for this approach can be found in a study by Althuisius et al. which advocates for ultrasound cervical length screening in pregnant women with a history of premature birth or miscarriage in the second trimester and cerclage placement only in cases where cervical length less than $25 \mathrm{~mm}$ is found [9]. Shift in practice was firstly seen in University hospital Rijeka where significant decline in cervical procedures occurred when cervical cerclage rate fell from $1.93 \%$ in 1994 to $0.77 \%$ in 1995 and remained under $1 \%$ thereafter. The same shift in University hospital Merkur occured ten years later when cervical cerclage rate fell from $1.29 \%$ in 2004 to $0.52 \%$ in 2005 . The administration of progesterone as a therapeutic agent for the prevention of preterm birth dates to the early 1960s [10], however it's more substantial utilisation started only after randomized controlled trials were published in 2003 showing its effectiveness [11,12]. In University hospital Rijeka and University hospital Merkur cervical cerclage was favoured procedure for patients with prior preterm birth and cervical length shortening. More significant use of vaginal or intramuscular progesterone started only after 2005. Accordingly it is unlikely that progesteron use significantly influenced preterm birth rates at that time. Similarly in 2003. first trials of possible efficacy of cervical pessary for prevention of preterm birth emerged [13]. However in both institutions this strategy was never utilised. In the observed period, regardless of the reduction in the number of cerclage procedures, the number of preterm births did not changed significantly (Figure 2). Increased number of poorly controlled pregnancies during war in Croatia and the postwar period (1994-1998) resulted in slight increase in preterm birth rate (7-8\%) [14]. In the period from 2001 to 2010 preterm birth rate decreased to $5.8 \%$ [15]. The rate of preterm birth was stable in both centers and similar to national preterm birth rates, ranging from $4.16 \%$ to $5.18 \%$ (Figure 1a\&1b). Despite significantly lower number of cerclage procedures, the rate of premature births remained low and stable. Certain limitations of our analysis can be found in it's retrospective character and data obtained from two different centers. However University hospital Rijeka and University hospital Merkur were chosen intentionally 
because of regional representativity and differences in clinical practice which is common in Croatia due to lack of national guidelines and national data on cerclage procedures. Study period was also chosen intentionally because the most significant changes in clinical practice regarding preterm birth and cervical cerclage procedures occurred at that time. Therefore, although differences between the statistical data of two institutions are evident, it does not diminish the importance of adopted conclusions because they are based on a large number of patients.

\section{Conclusion}

In conclusion due to recent recommendations significant reduction of ineffective cerclage procedures has been made without increasement of preterm birth rates. Although we are aware of multifactorial cause of premature birth, our study shows that increase in the number of cerclage above the one percent does not cause further reduction in the preterm birth rate. Given these results, our opinion is that the number of cerclage should not exceed $1 \%$. Cervical cerclage remains important procedure in prevention of preterm birth if the condition of careful selection of patients who would benefit from such procedure is met.

\section{References}

1. Larroque B, Ancel PY, Marret S, Marchand L, Andre M, et al. (2008) Neurodevelopmental disabilities and special care of 5-year-old children born before 33 weeks of gestation (the EPIPAGE study): a longitudinal cohort study. Lancet 371(9615): 813-820.

2. Blencowe H, Cousens S, Oestergaard MZ, Chou D, Moller AB, et al. (2012) National, regional, and worldwide estimates of preterm birth rates in the year 2010 with time trends since 1990 for selected countries: a systematic analysis and implications. Lancet 379(9832): 2162-2172.

3. Shirodkar VN (1955) A new method of operative treatment for habitual abortions in the second trimester of pregnancy. Antiseptic 52: 299-300.

4. McDonald IA (1957) Suture of the cervix for inevitable miscarriage. J Obstet Gynecol 64(3): 346-350.
5. Berghella V, Odibo AO, To MS, Rust OA, Althuisius SM, et al. (2005) Cerclage for short cervix on ultrasound: Meta-analysis of trials using individual patient-level data. Obstet Gynecol 106(1): 181-189.

6. To MS, Alfirevic Z, Heath VC, Cicero S, Cacho AM, et al. (2004) Cervical cerclage for prevention of preterm delivery in women with short cervix: randomised controlled trial. Lancet 363(9424): 1849-1853.

7. To MS, Palaniappan V, Skentou C, Gibb D, Nicolaides KH, et al. (2002) Elective cerclage vs. ultrasound-indicated cerclage in high-risk pregnancies. Ultrasound Obstet Gynecol 19(5): 475-477.

8. MRC/RCOG Working Party on Cervical Cerclage (1993) Final report of the Medical Research Council/Royal College of Obstetricians and Gynaecologists multicentre randomised trial of cervical cerclage. Br J Obstet Gynaecol 100(6): 516-523.

9. Althuisius SM, Dekker GA, Hummel P, Bekedam DJ, Geijn VHP, et al. (2001) Final results of the cervical incompetence prevention randomized cerclage trial (CIPRACT): therapeutic cerclage with bed rest versus bed rest alone. Am J Obstet Gynecol 185(5): 1106-1112.

10. LeVine L (1964) Habitual abortion. A controlled clinical study of progestational therapy. West J Surg 72: 30-36.

11. Fonseca DEB, Bittar RE, Carvalho MHB, Zugaib M (2003) Prophylactic administration of progesterone by vaginal suppository to reduce the incidence of spontaneous preterm birth in women at increased risk: a randomized placebo-controlled double-blind study. Am J Obstet Gynecol 188(2): 419-424.

12. Meis PJ, Klebanoff M, Thom E, Mitchell P, Sibai B, et al. (2003) Prevention of recurrent preterm delivery by 17-alpha hydroxyprogesterone caproate. N Engl J Med 348(24): 2379-2385.

13. Arabin B, Halbesma JR, Vork F, Hubener M, Eyck VJ, et al. (2003) Is treatment with vaginal pessaries an option in patients with a sonographically detected short cervix? J Perinat Med 31(12): 122-133.

14. Drazancic A, Rodin U, Filipovic GB (2007) Perinatal care in Croatia yesterday, today, tomorrow. Lijecnicki Vjesnik 1299(3-4): 87-99.

15. Rodin U, Filipovic GB, Drazancic A (2011) Births and perinatal mortality of very low birth weight newborns in Croatia in the 2001-2010 period. Gynaecologia et Perinatologia 20: 46-50.

\section{Your next submission with Juniper Publishers will reach you the below assets}

- Quality Editorial service

- Swift Peer Review

- Reprints availability

- E-prints Service

- Manuscript Podcast for convenient understanding

- Global attainment for your research

- Manuscript accessibility in different formats

( Pdf, E-pub, Full Tsext, Audio)

- Unceasing customer service

Track the below URL for one-step submission https://juniperpublishers.com/online-submission.php 